\title{
Editorial: Linking Advancement Research and Practice
}

Since becoming editor of this journal just a year ago, I have become keenly aware of the gulf that separates the perspectives of academic researchers and advancement practitioners. I must acknowledge that I was always aware of those different perspectives, but did not fully appreciate the extent of the gap and had not given much thought to why it exists.

In this year as editor, I have read a number of research-based papers that reflect solid research methodology and reach conclusions fully supported by the data, but are of limited, if any, use to practitioners because they are based on assumptions about "how things work" that are at variance with what actually occurs in the real world. I am reluctant to cite even a hypothetical example at risk of seeming to diminish some individual's worthy efforts, but all who have worked in advancement surely can develop their own examples of instances in which "everybody knows" how something is actually done, even though the textbooks describe a more "rational" process as the ideal. Some practitioners who have been asked to review certain papers have not been shy about noting researchers' flawed assumptions when writing their confidential and anonymous review comments to the editor. In addition, too often, academic writers who address advancement from the perspective of their own disciplines are writing for their academic peers, not practitioners, and use terminology and references incomprehensible to any reader outside of their specialty.
On the other hand, some practitioner reactions to research-based articles reveal their own lack of understanding about the role and process of academic research. Some practitioners may react with, in essence, "Duh" to some researcher's conclusion that a point of advancement's conventional wisdom is true. Others criticize research as addressing trivial points. They are sometimes right and sometimes they just don't fully understand the purpose and intent of the research activity.

First, it is important to keep in mind the distinction between basic and applied research. Basic research seeks to answer fundamental questions in studies that over time develop a body of knowledge and create a foundation for the formulation of theories. Applied research is more immediately relevant to practice. While many advancement practitioners understandably feel the need for the latter, they should not mistake the former for the latter; that is, the fact that research may not be immediately applicable is not necessarily its weakness if its intention is rather to develop the intellectual base of the profession over time.

Moreover, research that applies sound methodology to support a point of conventional wisdom, however self-evident or trivial it may seem, makes a contribution toward establishing that point as a part of something more than "folklore" or even "conventional wisdom;" rather, it establishes the principle as part of the profession's body 
of research-based knowledge. It is one thing to say something is true because "everybody knows it" or "it's obvious" and another to give a credible response to the question "How do you know?"

And, while some research questions may be so narrowly focused as to seem trivial, a beach is built one grain of sand at a time. It is necessary to focus a research study on a specific question or questions in order to maintain the rigor of methodology. No one study changes the world, but the accumulation of study upon study eventually develops a body of professional knowledge that informs practice.

The gulf between advancement practitioners and scholars who study the field is perhaps greater than between practitioners and researchers in some other professions because there are few university-based academic programs in advancement that are conducted by fulltime faculty who also train practitioners for the field. What little university teaching does occur related to advancement is still mostly based on the insights of practitioners. What research is undertaken usually emanates from schools of business or education and is guided by professors for whom advancement is at best a secondary interest.

Two things need to be done. First, we need to do a better job of meeting practitioners' needs for applied research and for data that is vital to their success right now. And, second, we need to develop better avenues of dialog between advancement practitioners and academic researchers so that basic research in the field will be based on realistic assumptions and relevant questions and so that its value will be better appreciated by advancement professionals.
There is a need to create new forums in which advancement practitioners and academic researchers can talk. Dialog could help to enhance their understanding of the other's reality and establish an agenda for research that will be academically sound and of practical benefit as well. In the 1980s, University of Maryland Professor Robert Carbone undertook to develop an agenda for research in fund raising, which received wide attention from potential researchers. Broad priority areas for research was also a principal outcome of the Greenbriar II conference hosted by CASE in 1985. But years have passed and the research agenda for this decade is unclear. (The term "Greenbriar II" as the name of a CASE conference has almost no recognition among today's practitioners and, ironically and amusingly, is recognized by Google principally as the name of a retirement community in $\mathrm{New}$ Jersey!)

Finally, there is the issue of financial support. We need to be realistic in accepting that advancement research will not soon receive the kind of financial support that is available in other fields. I doubt that a National Institute for Advancement Research will soon come along to rival the National Institutes of Health or the National Science Foundation. Nor, in today's environment, is this likely to become an emphasis of many existing foundations.

Most of the applied research today is being conducted by commercial consulting firms supported by client fees. There is obviously little incentive for institutions to fund anything that does not result, at least potentially, in improved performance right away. If basic research is to move beyond practitioners' doctoral 
dissertations and the occasional side trip by a marketing or communications professor, there will need to be sources of grants to support such work and create incentives for full-time scholars to move into this space. How to address this need will be a worthy topic of consideration by
CASE and its commissions in the years ahead.

Michael J. Worth Professor of Nonprofit Management, The George Washington University, Washington, DC 